\title{
PERENCANAAN PENGEMBANGAN WISATA PANTAI BERBASIS POTENSI SUMBERDAYA ALAM DAN DAYA DUKUNG KAWASAN DI DESA SAWARNA, BANTEN \\ (Coastal Tourism Development Based on Natural Resources and Carrying Capacity in Sawarna Village, Banten)
}

\author{
Kaulina Silvitiani $^{*}$, Fredinan Yulianda ${ }^{2}$, dan Vincentius P Siregar ${ }^{3}$ \\ ${ }^{1}$ Sekolah Pascasarjana, Program Studi Pengelolaan Sumberdaya Pesisir, Institut Pertanian Bogor, \\ Gedung Sekolah Pascasarjana Lantai II Kampus IPB Baranangsiang Bogor 16144. \\ ${ }^{2}$ Departemen Manajemen Sumberdaya Perairan, Fakultas Perikanan dan Ilmu Kelautan, \\ Institut Pertanian Bogor, Jl. Agatis Kampus IPB Darmaga, Bogor 16680. \\ ${ }^{3}$ Departemen Teknologi dan Ilmu Kelautan, Fakultas Perikanan dan Ilmu Kelautan, \\ Institut Pertanian Bogor, Jl. Agatis Kampus IPB Darmaga, Bogor 16680.
}

*Penulis korespondensi. Tel: 6282110074760. Email: kaulinasilvitiani@ gmail.com.

Diterima: 17 Maret 2017

Disetujui: 1 Mei 2017

\begin{abstract}
Abstrak
Sebagian besar kawasan pesisir di Indonesia merupakan kawasan alami yang memiliki potensi wisata dan belum dikembangkan secara optimal, salah satunya ialah kawasan pesisir Desa Sawarna yang berada di Kecamatan Bayah. Kegiatan wisata di daerah ini telah lama berlangsung, dan Desa Sawarna memiliki kawasan pantai yang luas dan indah dengan batu-batu karang yang menjadi salah satu daya tarik wisata. Tempat ini juga menjadi tempat wisata selancar oleh turis-turis mancanegara namun dalam pengelolaan masih sebatas oleh masyarakat lokal dan aparat desa. Tujuan dari penelitian ini yaitu menilai kesesuaian wisata pantai dan wisata selancar di Desa Sawarna, menilai daya dukung kawasan Desa Sawarna untuk menunjang kegiatan pengembangan wisata pantai dan selancar, kemudian menghasilkan arahan lokasi wisata pantai dan wisata selancar di Desa Sawarna. Metode yang digunakan adalah analisis kesesuaian wisata pantai dan wisata selancar guna menentukan kawasan wisata, analisis daya dukung kawasan guna mengestimasi daya tampung wisatawan dalam suatu kawasan. Berdasarkan analisis kesesuaian potensi sumberdaya alam yang dapat digunakan menjadi kawasan wisata pantai adalah Pantai Legon Pari, Pantai Karang Bereum, Pantai Tanjung Layar, Pantai Ciantir, Pantai Goa Langir dan Pantai Pulo Manuk. Sedangkan kawasan yang berpotensi dikembangkan sebagai lokasi wisata selancar antara lain Pantai Legon Pari, Pantai Ciantir dan Pantai Pulo Manuk. Pantai ciantir memiliki estimasi daya dukung ekologis yang paling tinggi yaitu sebanyak 567 orang/hari.
\end{abstract}

Kata kunci: daya dukung kawasan, kesesuaian wisata, pengembangan, wisata pantai, wisata selancar, wisata pesisir.

\begin{abstract}
Most coastal areas in Indonesia are natural areas that have tourism potential and not yet developed, one of which is the village Sawarna Coast region in Sub Bayah. Tourist activities in this area has long been underway, and the Village Sawarna have extensive coastal areas and beautiful with rocks that became one of the tourist attraction. The place is also a place of surfing by foreign tourists, but the management is still limited by the local community and village officials. The purpose of this study is assessing the suitability of coastal tourism and surfing in the village Sawarna, assessing the carrying capacity Sawarna Village area to support the development of coastal tourism and surfing, then generating leads beaches and tourist sites in the village Sawarna surfing. The method used is the analysis of the suitability of coastal tourism and surfing to determine the tourist area, the analysis of the carrying capacity of the region to estimate the capacity of tourists in an area. Based on the analysis of the suitability of potential natural resources can be used as coastal resorts are Legon Pari Beach, Karang Bereum Beach, Tanjung Layar Beach, Ciantir Beach, Goa Langir Beach and Pulo Manuk Beach. While the region has the potential to be developed as a tourist destination among others Coast surfing are Legon Pari Beach, Ciantir Beach, m Pulo Manuk Beach. Ciantir Beach has estimated the ecological carrying capacity of the highest of 567 people/day.
\end{abstract}

Keywords: beach tourism, carrying capacity area, coastal tourism development, suitability tourism, surfing tourism.

\section{PENDAHULUAN}

Ekosistem pesisir dan laut memiliki potensi yang besar dan dapat dimanfaatkan untuk kepentingan pariwisata, salah satunya kegiatan wisata pesisir dan laut di Indonesia adalah wisata pantai. Wisata pantai merupakan suatu bentuk kegiatan wisata yang dilakukan di daerah pantai yang umumnya memanfaatkan sumberdaya pantai (Putera dkk, 2013). Salah satu kategori wisata 
pantai adalah rekreasi pantai yang merupakan kegiatan rekreasi dengan memanfaatkan sumberdaya pantai seperti pasir putih, pemandangan, hamparan pantai dan perairan pantainya (Yulianda dkk, 2010). Pengembangan kawasan pantai untuk keperluan rekreasi di Indonesia dewasa ini cenderung meningkat kegiatannya bersamaan dengan semakin digiatkannya bidang kepariwisataan, selain itu kepariwisataan juga dapat menunjang perekonomian lokal (Sobari dkk, 2006).

Sebagian besar kawasan pesisir di Indonesia merupakan kawasan alami yang memiliki potensi wisata dan belum dikembangkan secara optimal, salah satunya ialah kawasan Pesisir Desa Sawarna yang berada di Kecamatan Bayah. Pengembangan kawasan peruntukan pariwisata didasarkan pada wilayah-wilayah yang memiliki obyek dan daya tarik wisata serta tersedianya dukungan sarana dan prasarana pariwisata (Anonim, 2014). Menurut Blancas dkk, (2013) untuk perencanaan model pariwisata harus berdasarkan pada keragaman, kualitas dan keberlanjutan agar dapat meningkatkan daya saing daerah tujuan wisata. Kebijakan daerah yang tertuang pada Pada Rencana Tata Ruang Wilayah (RTRW) Kabupaten Lebak bahwa kawasan Desa sawarna merupakan kawasan kegiatan rekreasi pantai dan wisata bahari (Anonim, 2014). Kegiatan wisata di daerah ini telah lama berlangsung, dan Desa Sawarna memiliki kawasan pantai yang luas dan indah dengan batu-batu karang yang menjadi salah satu daya tarik wisata. Tempat ini juga menjadi tempat wisata selancar oleh turisturis mancanegara namun dalam pengelolaan masih sebatas oleh masyarakat lokal dan aparat desa.

Pada saat ini, banyak daerah di Indonesia yang telah menjadi tujuan wisata belum sepenuhnya mengantisipasi perkembangan pariwisata yaitu permintaan terhadap produk dan pelayanan yang berkualitas, baik melalui persiapan pengembangan kawasan yang atraktif dengan obyek atau atraksi yang menarik maupun infrastuktur dan aksesibilitas pariwisata yang menunjang, termasuk di Desa Sawarna. Di satu sisi pemerintah Desa Sawarna menjadikan pesisir Desa Sawarna sebagai kawasan pariwisata, namun di sisi lain upaya-upaya yang dilakukan untuk mencapai tujuan tersebut relatif masih terbatas, padahal kesiapan secara optimal sangat dibutuhkan untuk menuju tujuan yang diinginkan. Oleh karena itu, pembangunan dalam sektor pariwisata harus difokuskan namun dalam pembangunan tersebut harus mempertimbangkan aspek lingkungan, dan penting dalam hal ini memahami hal yang diinginkan oleh wisatawan sehingga prioritas pembangunan dalam kawasan wisata dapat ditetapkan (Philips dan House 2009).
Tujuan dari penelitian ini yaitu menilai kesesuaian wisata pantai dan wisata selancar di Desa Sawarna, menilai daya dukung kawasan Desa Sawarna untuk menunjang kegiatan pengembangan wisata pantai dan selancar, kemudian menghasilkan arahan lokasi wisata pantai dan wisata selancar di Desa Sawarna.

\section{METODE PENELITIAN}

\section{Waktu dan Lokasi}

Penelitian ini dilaksanakan pada bulan Maret sampai April 2015 dan bertempat di Pesisir Desa Sawarna Kecamatan Bayah Kabupaten Lebak, Banten.

\section{Prosedur \\ Metode pengumpulan data}

Penelitian ini menggunakan data primer dan data sekunder. Metode yang digunakan untuk pengambilan data primer adalah metode survei. Data primer tediri atas, keadaan umum lokasi penelitian, data fisik kawasan. Pengumpulan data dilakukan di daerah pantai dengan cara purposive sampling yaitu berdasarkan kawasan pantai yang dapat dijangkau oleh wisatawan. Sedangkan data sekuder merupakan, data yang diperoleh dari studi kepustakaan atau data dari hasil penelitian/kajian orang atau instansi lain yang memiliki hubungan dengan penelitian ini sehingga dapat dijadikan data pendukung dalam penelitian ini.

\section{Metode analisis data \\ Analisis kesesuaian wisata}

Analisis kesesuaian wisata memiliki keterkaitan dengan kegiatan di sekitar kawasan pantai seperti bermain pasir, olahraga pantai, berenang, berjemur dan kegiatan lainnya. Menurut Yulianda dkk, (2010), terdapat 10 parameter kesusaian lahan untuk kegiatan wisata rekreasi di pantai kategori rekreasi (Tabel 1). Pada wisata pantai kategori selancar memiliki lima parameter untuk kesesuaian lahannya (Tabel 2). Rumus yang digunakan adalah rumus Indeks Kesesuaian Wisata (IKW) (Yulianda dkk, 2010):

$\mathbb{K} W=\Sigma\left[\mathrm{N}_{1} / \mathrm{Nmaks}_{\mathrm{N}}\right] \times 100 \%$

Keterangan:

$\mathrm{IKW}=$ Indeks kesesuaian wisata

$\mathrm{Ni} \quad=$ Nilai parameter ke-i

Nmaks $=$ Nilai maksimum dari suatau kategori wisata

\section{Analisis daya dukung}

Yulianda dkk, (2010) menyatakan bahwa daya dukung adalah kemampuan untuk menerima wisatawan dengan penggunaan sumberdaya alam 
Tabel 1. Kriteria kesesuaian wisata pantai kategori rekreasi

\begin{tabular}{|c|c|c|c|c|c|c|c|c|c|}
\hline Parameter & Bobot & $\begin{array}{l}\text { Kategori } \\
\text { S1 }\end{array}$ & Skor & $\begin{array}{l}\text { Kategori } \\
\text { S2 }\end{array}$ & Skor & $\begin{array}{l}\text { Kategori } \\
\text { S3 }\end{array}$ & Skor & $\begin{array}{l}\text { Kategori } \\
\mathrm{N}\end{array}$ & Skor \\
\hline $\begin{array}{l}\text { Kedalaman perairan } \\
\text { (m) }\end{array}$ & 5 & $0-3$ & 3 & $>3-6$ & 2 & $>6-10$ & 1 & $>10$ & 0 \\
\hline Tipe pantai & 5 & $\begin{array}{l}\text { Pasir } \\
\text { putih }\end{array}$ & 3 & $\begin{array}{l}\text { Pasir } \\
\text { putih, } \\
\text { berbatu }\end{array}$ & 2 & $\begin{array}{l}\text { Pasir putih, } \\
\text { berbatu } \\
\text { sedikit terjal }\end{array}$ & 1 & $\begin{array}{l}\text { Berbatu, } \\
\text { terjal }\end{array}$ & 0 \\
\hline Lebar pantai (m) & 5 & $>15$ & 3 & $10-15$ & 2 & $3-<10^{\circ}$ & 1 & $<3$ & 0 \\
\hline $\begin{array}{l}\text { Material dasar } \\
\text { perairan }\end{array}$ & 3 & Pasir & 3 & $\begin{array}{c}\text { Pasir } \\
\text { berkarang }\end{array}$ & 2 & $\begin{array}{c}\text { Pasir } \\
\text { berlumpur }\end{array}$ & 1 & $\begin{array}{c}\text { Bebatuan } \\
\text { karang }\end{array}$ & 0 \\
\hline $\begin{array}{l}\text { Kecepatan arus } \\
(\mathrm{m} / \mathrm{d})\end{array}$ & 3 & $0-0.17$ & 3 & $\begin{array}{c}>0.17- \\
0.34\end{array}$ & 2 & $>0.34-0.51$ & 1 & $>0.51$ & 0 \\
\hline $\begin{array}{l}\text { Kemiringan Pantai } \\
\left(^{\circ}\right)\end{array}$ & 3 & $<10$ & 3 & $10-25$ & 2 & $>25-45$ & 1 & $>45$ & 0 \\
\hline $\begin{array}{l}\text { Kecerahan perairan } \\
\text { (m) }\end{array}$ & 3 & $>5$ & 3 & $>3-5$ & 2 & $3-1$ & 1 & $<1$ & 0 \\
\hline $\begin{array}{l}\text { Penutupan lahan } \\
\text { pantai }\end{array}$ & 1 & $\begin{array}{l}\text { Lahan } \\
\text { terbuka, } \\
\text { kelapa }\end{array}$ & 3 & $\begin{array}{c}\text { Semak } \\
\text { belukar } \\
\text { rendah, } \\
\text { savana }\end{array}$ & 2 & $\begin{array}{c}\text { Belukar } \\
\text { tinggi, } \\
\text { pemukiman, } \\
\text { pelabuhan }\end{array}$ & 1 & $\begin{array}{c}\text { Hutan } \\
\text { bakau, } \\
\text { pemukiman } \\
\text {, pelabuhan }\end{array}$ & 0 \\
\hline Biota berbahaya & 1 & $\begin{array}{l}\text { Tidak } \\
\text { ada }\end{array}$ & 3 & $\begin{array}{l}\text { Satu } \\
\text { spesies }\end{array}$ & 2 & $\begin{array}{l}\text { Dua } \\
\text { spesies }\end{array}$ & 1 & $\begin{array}{l}\text { Lebih dari } \\
\text { dua spesies }\end{array}$ & 0 \\
\hline $\begin{array}{l}\text { Ketersediaan air } \\
\text { tawar }\end{array}$ & 1 & $\begin{array}{l}<0,5 \\
(\mathrm{~km})\end{array}$ & 3 & $\begin{array}{c}<0,5-1 \\
(\mathrm{~km})\end{array}$ & 2 & $>1-2$ & 1 & $>2(\mathrm{~km})$ & 0 \\
\hline
\end{tabular}

Sumber: Modifikasi Yulianda (2007)

Nilai maksimum $=($ Skor $x$ Bobot $)$ di mana nilai maksimum $=84$

Tabel 2. Kriteria kesesuaian wisata pantai kategori wisata selancar

\begin{tabular}{|c|c|c|c|c|c|c|c|c|c|}
\hline Parameter & Bobot & $\begin{array}{c}\text { Kategori } \\
\text { S1 }\end{array}$ & Skor & $\begin{array}{l}\text { Kategori } \\
\text { S2 }\end{array}$ & Skor & $\begin{array}{l}\text { Kategori } \\
\text { S3 }\end{array}$ & Skor & $\begin{array}{c}\text { Kategori } \\
\mathrm{N}\end{array}$ & Skor \\
\hline $\begin{array}{l}\text { Tinggi gelombang } \\
\text { (meter) }\end{array}$ & 5 & $>2$ & 3 & $1,5-2$ & 2 & $1-1,5$ & 1 & $<1$ & 0 \\
\hline $\begin{array}{l}\text { Panjang } \\
\text { gelombang (meter) }\end{array}$ & 5 & $>100$ & 3 & $50-100$ & 2 & $10-50$ & 1 & $<10$ & 0 \\
\hline $\begin{array}{l}\text { Jenis pecah } \\
\text { gelombang }\end{array}$ & 4 & $\begin{array}{l}\text { Plunging } \\
\text { and } \\
\text { collapsing }\end{array}$ & 3 & collapsing & 2 & Spilling & 1 & Surging & 0 \\
\hline $\begin{array}{l}\text { Material dasar } \\
\text { perairan }\end{array}$ & 3 & Berkarang & 3 & $\begin{array}{c}\text { Pasir, } \\
\text { berkarang }\end{array}$ & 2 & Pasir, & 1 & Lumpur & 0 \\
\hline $\begin{array}{l}\text { Kedalaman } \\
\text { perairan (meter) }\end{array}$ & 3 & $>5$ & 3 & $3-5$ & 2 & $1,5-3$ & 1 & $<1,5$ & 0 \\
\hline
\end{tabular}

Sumber: Modifikasi Hakim (2007), Aziz dkk, (2012) dan Konsultasi Pakar

Nilai maksimum $=($ Skor $\mathrm{x}$ Bobot $)$ di mana nilai maksimum $=60$

Keterangan: $\quad$ S1 $=$ Sangat sesuai dengan nilai $75-100 \%$

S2 = Sesuai dengan nilai $50-<75 \%$

S3 = Sesuai bersyarat dengan nilai $25-<50 \%$

$\mathrm{N} \quad=$ Tidak sesuai dengan nilai $<25 \%$

secara maksimum dan terus menerus tanpa merusak lingkungan. Daya dukung dari suatu wilayah memiliki definisi lain yaitu kenyamanan pengunjung dalam melakukan kegiatan (potensi ekologi) dalam hal area yang digunakan untuk kegiatan tersebut, dan hal ini dipengaruhi oleh jam oprasional daerah dan waktu yang dihabiskan oleh pengunjung dalam melakukan kegiatan tersebut (Pangemanan dkk, 2012). Rumus daya dukung untuk pengembangan ekowisata denga menggunakan konsep daya dukung kawasan (DDK) (Yulianda dkk, 2010):

$$
\mathrm{DDK}=\mathrm{K} \times(\mathrm{Lp} / \mathrm{Lt} \times \mathrm{Wt} / \mathrm{Wp})
$$

di mana :

DDK = Daya dukung kawasan

$\mathrm{K}=$ Potensi ekologis pengunjung persatuan unit area

Lp = Luasan area atau panjang area yang dapat dimanfaatkan $\left(\mathrm{m}^{2}\right)$

Lt = Unit area atau panjang area yang dimanfaatkan $\left(\mathrm{m}^{2}\right)$

$\mathrm{Wt}=$ Waktu yang disediakan oleh kawasan untuk kegiatan wisata dalam satu hari (jam) 
$\mathrm{Wp}=$ Waktu yang dihabiskan oleh pengunjung untuk setiap kategori tertentu (jam)

\section{HASIL DAN PEMBAHASAN}

\section{Kesesuaian Wisata}

Hasil analisis kesesuaian kawasan untuk pengembangan wisata pantai kategori rekreasi pada di sepanjang kawasan pesisir Desa Sawarna diperoleh empat kategori kelas kesesuaian yaitu kelas kesesuaian S1 (sangat sesuai), kelas kesesuaian S2 (sesuai), dan kelas kesesuaian S3 (sesuai bersyarat) dan kelas kesesuaian $\mathrm{N}$ (tidak sesuai) (Gambar 1). Pertama, kelas kesesuaian S1 atau bisa disebut kelas sangat sesuai, yaitu kawasan pantai yang sangat sesuai untuk dikembangkan sebagai kawasan kegiatan wisata. Kawasan tersebut dapat dikatakan sangat sesuai apabila nilai IKW kawasan tersebut mencapai antara $75-100 \%$.

Ada dua pantai yang termasuk dalam kelas S1 ini, yaitu Pantai Legon Pari dan Pantai Ciantir. Kedua, kelas kesesuaian S2 atau yang bisa disebut sesuai, yaitu kawasan pantai yang sesuai untuk dikembangkan sebagai kawasan kegiatan wisata namun terdapat beberapa faktor pembatas untuk dapat mengembangkan kegiatan wisata di kawasan tersebut tetapi faktor pembatas tersebut tidak mengurangi kesesuaian kawasan tersebut untuk dilakukannya kegiatan wisata. Kawasan tersebut dapat dikatakan sangat sesuai apabila nilai IKW kawasan tersebut mencapai antara $50-<75 \%$.

Pantai yang memiliki kelas kesesuaian S3 ada empat pantai, yaitu Pantai Karang Bereum, Pantai Tanjung Layar, Pantai Goa Langir dan Pantai Pulo Manuk. Selain kelas kesesuaian S1 dan S2, di kawasan pesisir Desa Sawarna terdapat kawasan yang memiliki kelas kesesuaian S3 yaitu Pantai Karang Bokor. Kelas kesesuaian S3 atau bisa disebut sesuai bersyarat, di mana kawasan pantai tersebut sesuai untuk dikembangkan menjadi kawasan kegiatan, namun ada beberapa faktor pembatas yang membatasi kawasan tersebut sehingga harus syarat yang dipenuhi agar faktor pembatas yang ada di kawasan tesebut tidak mempengaruhi kegiatan wisata di kawasan pantai.

Hasil analisis kesesuaian kawasan wisata untuk kategori selancar di kawasan pesisir Desa Sawarna diperoleh tiga kategori kelas kesesuaian yaitu kelas kesesuaian S1 (sangat sesuai), kelas kesesuaian S2 (sesuai), dan kelas kesesuaian $\mathrm{N}$ (tidak sesuai) (Gambar 2). Pertama, kelas kesesuaian S1 atau bisa disebut kawasan yangsangat sesuai untuk dikembangkan sebagai kawasan wisata kategori wisata selancar. Kawasan tersebut dapat dikatakan sangat sesuai apabila nilai IKW kawasan tersebut mencapai nilai $75-100 \%$.
Pantai yang memiliki kelas kesesuaian S1 adalah Pantai Ciantir, pada bulan-bulan tertentu ombak di lokasi pantai ini bisa mencapai 0,5-3 meter dan ombak di lokasi ini sudah termasuk ke dalam ombak kelas internasional. Kedua, kelas kesesuaian S2 atau bisa disebut kawasan yang sesuai untuk dikembangkan menjadi kawasan wisata kategori wisata selancar. Kawasan yang dikatakan termasuk dalam kelas kesesuaian S2 yaitu kawasan tersebut memiliki nilai IKW mencapai $50-<75 \%$. Pantai yang memiliki kelas kesesuaian S2 yaitu Pantai Legon Pari, Pantai Goa Langir dan Pantai Pulo Manuk. Ketiga yaitu kelas kesesuaian $\mathrm{N}$ atau bisa disebut kawasan yang tidak sesuai untuk dikembangkan wisata pantai kategori selancar, dikarenakan terdapat beberapa faktor pembatas yang membatasi kawasan tersebut menjadi kawasan wisata pantai kategori selancar.

Terdapat tiga pantai yang termasuk ke dalam kelas kesesuaian ini yaitu Pantai Karang Bereum, Pantai Tanjung Layar dan Pantai Karang Bokor. Kawasan pantai-pantai ini didominasi oleh bebatuan karang yang curam yang mengakibatkan kurangnya kualitas ombak yang mempengaruhi jenis pecah gelombangnya, lokasinya menjadi lebih berbahaya dan sulit dijangkau.

\section{Daya Dukung Wisata}

Konsep daya dukung kawasan berasal dari persepsi bahwa wisata tidak bisa terus berkembang di kawasan tertentu tanpa menyebabkan kerusakan yang permanen pada kawasan itu sendiri (Jurado $d k k$, 2013). Dikemukakan juga bahwa mengemukakan bahwa daya dukung merupakan suatu alat oprasional untuk mencapai kegiatan wisata yang berkelanjutan, karena tidak ada keberlanjutan tanpa batasan. Kawasan pantai berpasir putih merupakan salah satu faktor utama dalam penentuan pemanfaatan kawasan wisata pantai kategori rekreasi pantai. Oleh karena itu perkiraan daya dukung kawasan wisata pantai ditentukan dengan menghitung panjang pantai dengan berdasarkan peta tematik panjang pantai di kawasan pesisir Desa Sawarna, di mana semakin panjang kawasan suatu pantai yang digunakan untuk aktivitas wisata, maka semakin tinggi daya dukung ekologis kawasan tersebut. namun sebaliknya, semakin pendek kawasan suatu pantai yang digunakan untuk aktivitas wisata, maka semakin rendah daya dukung ekologis kawasan tersebut.

Pantai Ciantir memiliki kawasan pantai terpanjang di antara pantai yang ada, pantai ini memiliki panjang pantai mencapai 420 meter kemudian diikuti oleh Pantai Legon Pari dengan panjang pantai mencapai 335. Kedua pantai ini memiliki nilai daya dukung tertinggi sekitar 567- 


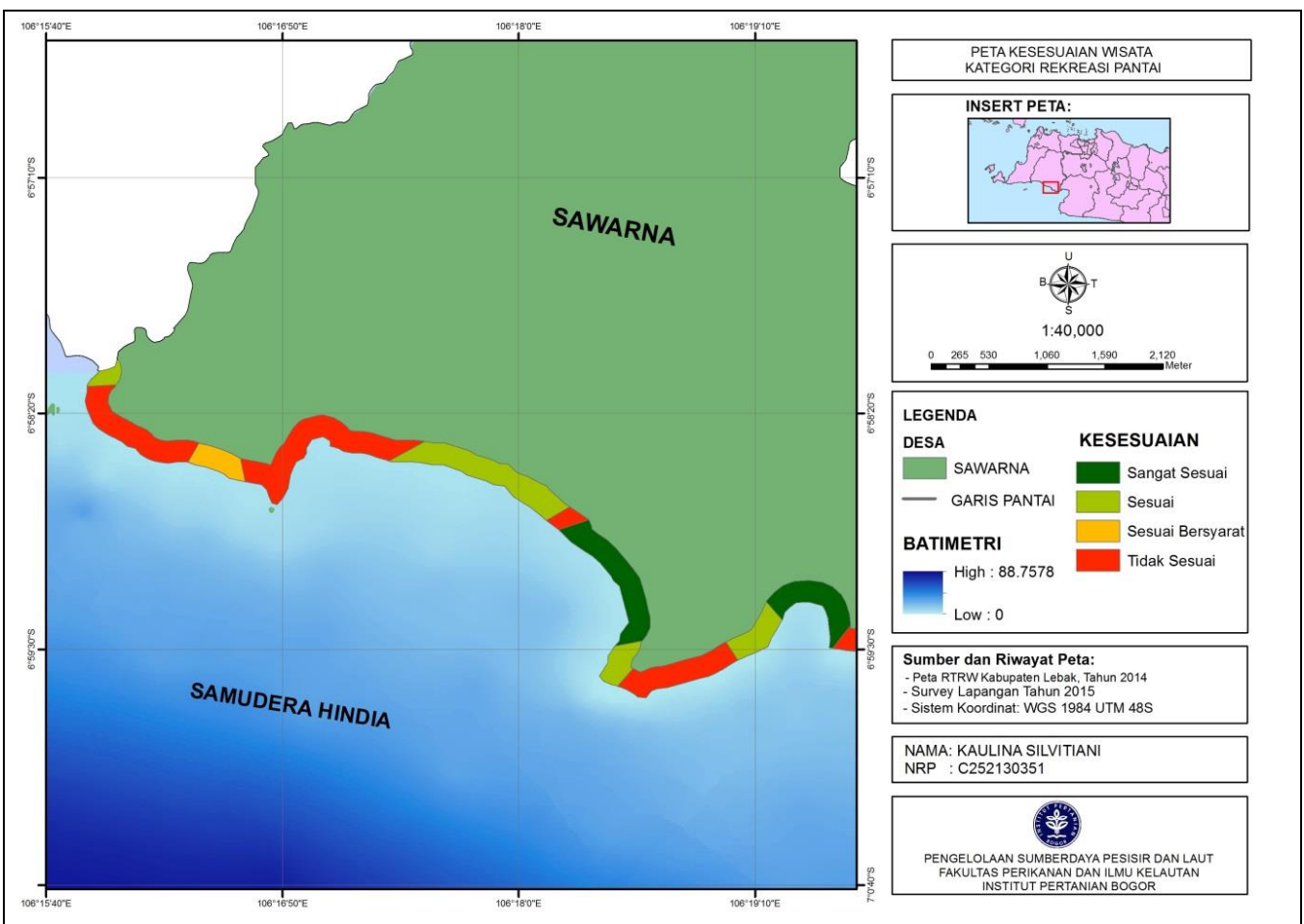

Gambar 1. Kesesuaian wisata pantai kategori rekreasi.

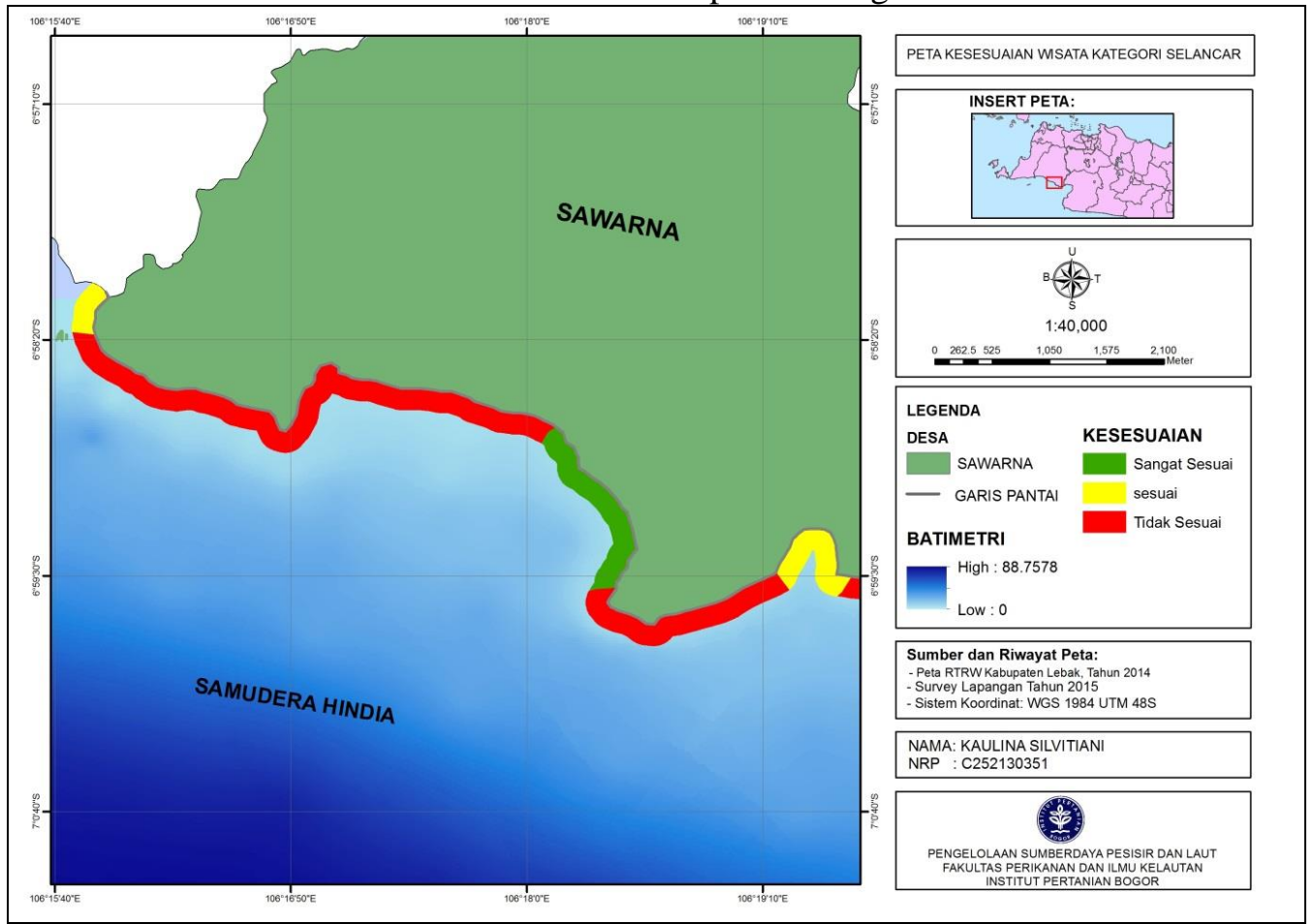

Gambar 2. Kesesuaian wisata pantai kategori selancar.

352 orang/hari. Pantai Karang Bokor merupakan kawasan dengan nilai daya dukung yang rendah yaitu 30 orang/hari, karena pantai ini memiliki panjang pantai hanya 88 meter (Tabel 3). Akses untuk ke Pantai Karang Bokor masih belum banyak yang mengetahuinya, dikarenakan belum adanya petunjuk jalan untuk menuju pantai ini. Kondisi pantai ini didominasi oleh batuan karang sehingga kegiatan wisata tidak banyak yang bisa dilakukan sehingga pantai ini memiliki daya dukung yang rendah.
Wisatawan yang mengunjungi dan menikmat suatu kawasan wisata, cepat atau lambat dapat merusak fungsi ekologi di kawasan tersebut, terlebih lagi apabila melebihi daya dukung ekologisnya. Maka dari itu, dalam pengelolaan suatu kawasan wisata sangat penting memperhatikan penilaian daya dukung sehingga dapat mengurangi dampak dan menjaga ekosistem di kawasan tersebut. Wei dkk, (2014) mengemukakan bahwa penilaian yang terintegrasi dari daya dukung kawasan dapat membantu dalam 
Tabel 3. Daya dukung ekologis kawasan pantai di Desa Sawarna.

\begin{tabular}{llcccccc}
\hline No & \multicolumn{1}{c}{ Lokasi } & $\begin{array}{c}\text { Panjang } \\
\text { pantai } \\
\end{array}$ & & \multicolumn{5}{c}{ Jenis kegiatan (orang/hari) } & DDK \\
\cline { 3 - 7 } & & $\begin{array}{c}\text { Rekreasi } \\
\text { pantai }\end{array}$ & $\begin{array}{c}\text { Voli } \\
\text { pantai }\end{array}$ & Selancar & Berjemur & $\begin{array}{c}\text { Orang/ } \\
\text { hari }\end{array}$ \\
\hline 1 & Pantai Legon Pari & 335 & 70 & 94 & 94 & 94 & 352 \\
2 & Pantai Karang & 120 & 11 & 14 & - & 14 & 39 \\
& Bereum & & & & & & 39 \\
3 & Pantai Tanjung Layar & 118 & 11 & 14 & - & 14 & 567 \\
4 & Pantai Ciantir & 420 & 113 & 151 & 151 & 151 & 39 \\
5 & Pantai Goa Langir & 120 & 11 & 14 & - & 14 & 19 \\
6 & Pantai Karang Bokor & 88 & 8 & - & - & 11 & 30 \\
7 & Pantai Pulo Manuk & 90 & 8 & - & 11 & 11 & \\
\hline
\end{tabular}

Sumber: Data primer, diolah (2015)

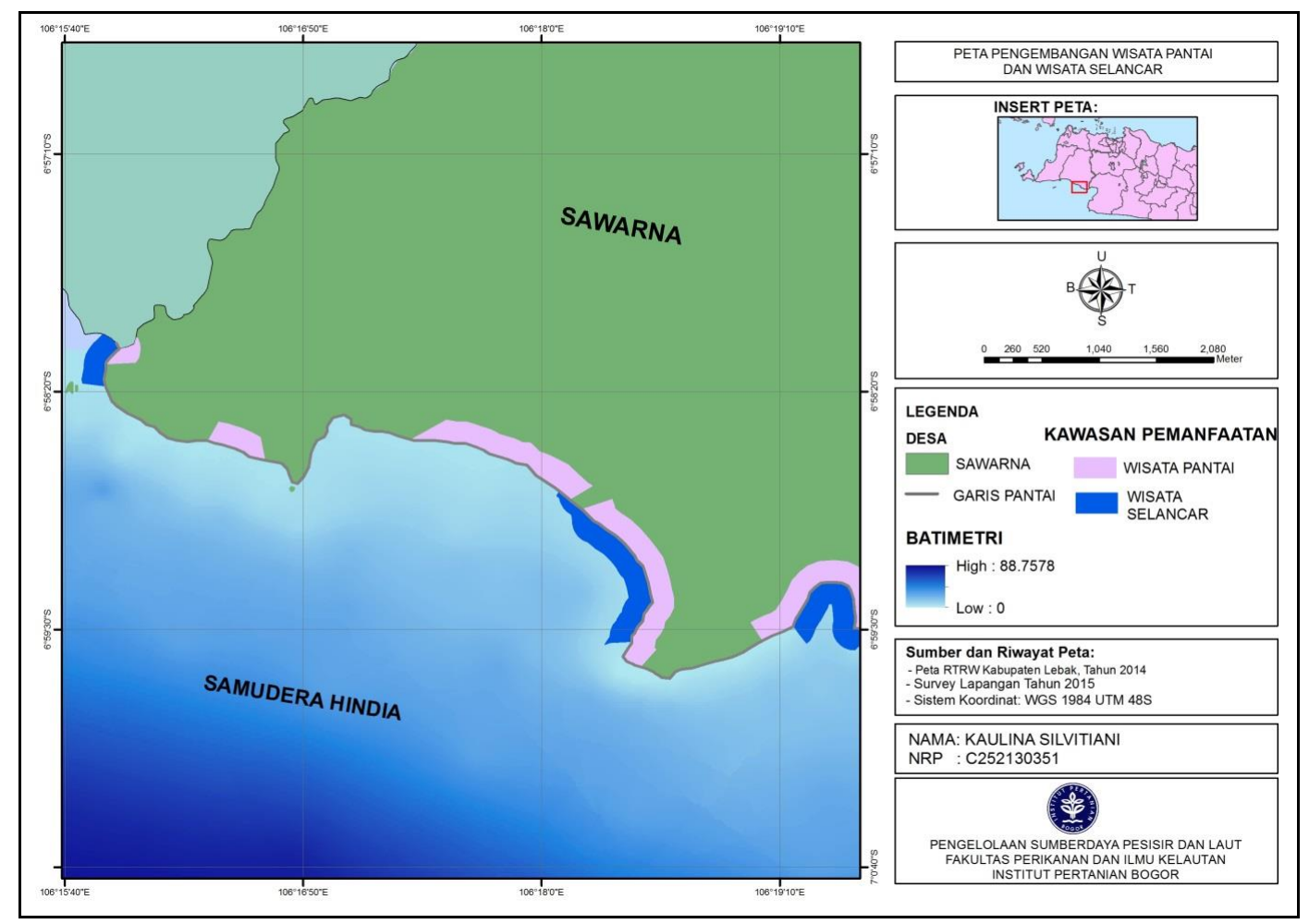

Gambar 3. Peta arahan lokasi pengembangan wisata pantai dan wisata selancar.

mendukung koordinasi dan pembangunan ekonomi dan ekologi di kawasan pesisir tersebut.

\section{Arahan lokasi Wisata Pantai dan Wisata Selancar}

Wisata pantai merupakan pangsa pasar terbesar di dalam pariwisata (Houston 2013; Lucrezi dkk, 2015), di mana dalam mengelola hal tersebut dilakukan dengan kurang baik, maka akan menyebabkan degradasi yang parah pada ekosistem pantai, penurunan pengunjung, dan kerugian ekonomi (Roca dkk, 2009; Schlacer dkk, 2014; Lucrezi dkk, 2015). Selaras dengan sasaran pengembangan yang nantinya akan dicapai Kabupaten Lebak dalam Rencana Tata Ruang Tahun 2014-2034 adalah penggunaan segala sumber daya yang tersedia secara optimal dengan tetap mempertimbangkan kelestarian alam dan lingkungan hidup baik untuk saat ini maupun saat mendatang, salah satunya dengan mengembangkan kawasan wisata. Dengan demikian dalam mengoptimalkan potensi sumberdaya alam pesisir Desa Sawarna maka perlu ditetapkan kawasankawasan yang nantinya akan dikembangkan menjadi kawasan wisata.

Arahan lokasi pengembangan kawasan wisata pantai dan selancar yang diperlihatkan pada Gambar 3 diperoleh berdasarkan hasil dari penggabungan klasifikasi kesesuaian wisata pantai dan kesesuaian wisata selancar dengan teknik overlay. Kawasan yang dapat dikembangkan menjadi kawasan wisata pantai sekaligus wisata selancar yaitu Pantai Legon Pari, Pantai Ciantir dan Pantai Pulo Manuk. Kemudian kawasan yang hanya 
dapat dikembangkan menjadi kawasan wisata pantai yaitu Pantai Goa Langir dan Pantai Karang Bokor. Penerapan Arahan ini disesuaikan dengan krateristik lingkungan yaitu potensi sumberdaya alam yang nantinya menjadi potensi wisata dan sumberdaya masyarakat di kawasan itu sendiri.

\section{KESIMPULAN}

Berdasarkan analisis kesesuaian potensi sumberdaya alam yang dapat digunakan menjadi kawasan wisata pantai adalah Pantai Legon Pari, Pantai Karang Bereum, Pantai Tanjung Layar, Pantai Cianti, Pantai Goa Langir dan Pantai Pulo manuk. Sedangkan kawasan yang berpotensi dikembangkan sebagai lokasi wisata selancar antara lain Pantai Legon Pari, Pantai Ciantir dan Pantai Pulo Manuk. Pantai Ciantir memiliki estimasi daya dukung ekologis yang paling tinggi yaitu sebanyak 567 orang/hari. Dalam perencanaan pengembangan suatu 'kawasan tersebut dengan tetap mempertimbangkan kelestarian alam dan lingkungan agar kawasan wisata tetap terjaga dan terhindar dari ancaman kerusakan yang mampu menurunkan ekosistem di kawasan tersebut, yang dapat berdampak langsung pada perekonomian masyarakat di kawasan tersebut.

\section{DAFTAR PUSTAKA}

Anonim, 2014. Rencana Tata Ruang Wilayah (RTRW) Kabupaten Lebak 2014-2034 Materi Teknis. BAPPEDA Kabupaten Lebak, Banten

Aziz, Z., Petrus, S., dan Ibnu, P., 2012. Studi Kesesuaian Perairan Pantai Tanjung Setian Sebagai Kawasan Wisata Bahari Kabupaten Lampung Barat Provinsi Lampung. J. Marine Research. 1(2):125-134.

Blancas, F.J., Mercedes, G., Macarena, L.O., dan Fatima, F., 2010. The Assessment of Sustainable Tourism: Application to Spanish Coastal Destinations. Ecological Indicators. 10:484-492.

Hakim, L.A.F., 2007. Penentuan Zona Potensial Pariwisata Bahari di Pesisir Pantai Selatan Pulau Lombok, NTB dengan Menggunakan Sistem Informasi Geografis (SIG). Skripsi. Institut Pertanian Bogor. Bogor.

Houston, J.R., 2013. The Economic Value of Beaches: Update. Shore \& Beach. 81(1):3-11.

Jurado, E.N, Damian, I.M., dan Morales, A.F., 2013. Carrying Capacity Model Applied In
Coastal Destinations. Ann. Tourism Res., 43:119.

Lucrezi, S., Melville, S., dan Peet, V.D.M., 2015. Managing Beaches and Beachgoers: Lessons from and the Blue Flag Award. Tourism Management. 48:211-230.

Pangemanan, A., Maryunan, Luchman, H., dan Bobby, P., 2012. Economic Analysis of Bunaken Nasional Park Ecotourism Area Based on the Carrying Capacity and Visitation Level. Asian Transaction on Basic and Applied Sciences. 2(4):34-40.

Phiplips, M.R., dan House, C., 2009. An Evaluation of Priorities for Beach Tourism: Case Studies from South Wales, UK. Tourism Management, 30:176-183.

Putera, A.H.F., Fachrudin, A., Niken, T.M.P., dan Setyo, B.S., 2012. Kajian Keberlanjutan Pengelolaan Wisata Pantai di Pantai Pasir Putih Bira, Bulukumba, Sulawesi Selatan. Jurnal Penelitian dan Pengembangan Kepariwisataan Indonesia. 8(3):241-254.

Roca, E., Villares, M., dan Ortego, M.I., 2009. Assessing Public Perceptions on Beach Quality According to Beach Users' Profile: A Case Study in the Costa Brava (Spain). Tourism Management, 30(4):598-607.

Schlancher, T.A., Jones, A.R., Dugan, J.E., Wesston, M.A., Harris, L., dan Schoeman, D.S., 2014. Open-Coast Sandy Beaches and Coastan Dunes. In B. Maslo J L Lockwood (Eds). Coastal Conservation. Cambridge University Press. Cambridge. pp37-94.

Sobari, M.P., Gatot, Y., dan Desi, N., 2006. Analisis Permintaan Rekreasi dan Strategi Pengembangan Wisata Bahari Pantai Kalianda Resort, Kabupaten Lampung Selatan. Buletin Eonomi Perikanan. 6(3):26-39.

Yulianda, F., 2007. Ekowisata Bahari sebagai Alternatif Pemanfaatan Sumberdaya Pesisir Berbasis Konservasi.. Departemen Manajemen Sumberdaya Perairan Fakultas Perikanan dan Ilmu Kelautan Institut Pertanian Bogor, Bogor.

Yulianda, F., Fachrudin, A., Armin, A.H., Sri, H., Kusharjani, dan Ho, S.K., 2010. Pengelolaan Pesisir dan Laut Secara Terpadu. Pusdiklat Pelatihan Kehutanan-SECEM-KOICA, Bogor.

Wei, C., Zhong-Yang, G., Jian-Ping, W., dan ShuFeng, Y., 2014. Constucting an Assesment Indices Systems to Analyze Integrated Regional Carrying Capacity in the Coastal Zones - A Case in Nantong. Ocean \&Coastal Management. 93:51-59. 